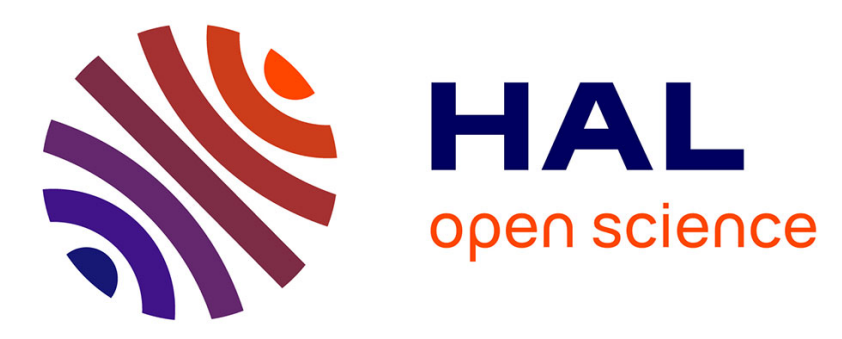

\title{
FT-IR and GC-MS analyses of Dressel IA amphorae from the Grand Congloué 2 wreck
}

Hitomi Fujii, Jean-Baptiste Mazzitelli, Dauren Adilbekov, Fabienne Olmer, Carole Mathe, Cathy Vieillescazes

\section{- To cite this version:}

Hitomi Fujii, Jean-Baptiste Mazzitelli, Dauren Adilbekov, Fabienne Olmer, Carole Mathe, et al.. FTIR and GC-MS analyses of Dressel IA amphorae from the Grand Congloué 2 wreck. Journal of Archaeological Science: Reports, 2019, 28, pp.102007. 10.1016/j.jasrep.2019.102007 . hal-02462744

HAL Id: hal-02462744

https://hal.science/hal-02462744

Submitted on 30 Mar 2020

HAL is a multi-disciplinary open access archive for the deposit and dissemination of scientific research documents, whether they are published or not. The documents may come from teaching and research institutions in France or abroad, or from public or private research centers.
L'archive ouverte pluridisciplinaire HAL, est destinée au dépôt et à la diffusion de documents scientifiques de niveau recherche, publiés ou non, émanant des établissements d'enseignement et de recherche français ou étrangers, des laboratoires publics ou privés. 


\title{
FT-IR and GC-MS analyses of Dressel IA amphorae from the Grand Congloué 2 wreck
}

\author{
Hitomi Fujii ${ }^{\mathrm{a}, *}$, Jean-Baptiste Mazzitelli ${ }^{\mathrm{a}}$, Dauren Adilbekov ${ }^{\mathrm{b}}$, Fabienne Olmer $^{\mathrm{c}}$, Carole Mathe ${ }^{\mathrm{a}, *}$, \\ Cathy Vieillescazes ${ }^{\mathrm{a}}$ \\ a IMBE UMR 7263/IRD237, Avignon University/CNRS/IRD/AMU, Restoration Engineering of Natural and Cultural Heritage, Faculty of Sciences, Campus Jean-Henri \\ Fabre, 301 rue Baruch de Spinoza BP 21239, 84916 Avignon Cedex 9, France \\ b IMBE UMR, Université d'Avignon University, ERASMUS MUNDUS MASTER IN ARCHaeological MATerials Science Student, France \\ ${ }^{\mathrm{c}}$ Centre Camille Jullian - UMR 7299, Maison Méditerranéenne des Sciences de l'Homme, Aix-en-Provence, France
}

\section{A R T I C L E I N F O}

\section{Keywords:}

Roman amphorae

Pitch

Wine

Tartaric acid

Syringic acid

FT-IR

GC-MS

\begin{abstract}
A B S T R A C T
This research work is focused on the chemical characterization of the substance present in the internal surfaces of Roman amphorae that made them waterproof and on the identification of their content. The samples come from the wreck of the Grand Congloue 2 that was studied in the Bay of Marseille by Commander Cousteau in 1952. The twenty studied amphorae are of type Dressel 1A and were provided by Cosa in Etruria (Tuscany, Italy). The FT-IR analysis indicated different bands concerning organic matter, as the chemical link O-H from carboxylic acid, C-H of the methylene group and C-O of the methyl ester. The study carried out by GC-MS showed nineteen diterpenoids, such as dehydroabietic acid and retene, which are chemical markers of Pinaceae family. Methyl ester by-products were also characterized and they revealed a pitch pyrogenically prepared from resinous wood (Pinus sp.). Principal Component Analysis allowed to group all of the twenty studied amphorae in two lots indicating two types of pitch. Concerning the content of these amphorae, the results from pitch as well as shards allowed to detect the presence of tartaric and syringic acids which are the main markers of the red wine. The comparison study between pitch and shard samples of same amphorae indicates that pitch analyses has permitted to obtain a high qualitative and quantitative proportion of wine markers.
\end{abstract}

\section{Introduction}

The analysis of organic residues present in amphorae can give important information to archaeologists. Diets, habits, technologies and original use of the vessels can be identified through these studies. This paper deals with Roman amphorae (Dressel IA) discovered in the Grand Congloue 2 wreck, one of the most famous ancient wrecks of all the coasts of the western Mediterranean. It was the first underwater archaeological excavation operation in the world thanks to the cooperation between the Commander Jacques-Yves Cousteau and Fernand Benoît (excavations were conducted between August 15th 1952 and June 30th 1957). The archaeological site of the wreck is located southeast of the bay of Marseille, near the Riou Island. From historical and archaeological points of view, two ships are stranded one on the other, exactly in the same place, a century apart. The archaeologist, Luc Long, published a study where two wrecks are clearly distinguished, thanks to the archaeological study of the furniture but also to the study of the excavation archives, where all elements contained on the ships are gathered (Olmer et al., 2015). The first one, the Grand-Congloue 1 was loaded mainly with nearly 400 Greek-Italic amphorae (sank between 220 and 180 BCE). The cargo of the second ship, the GrandCongloué 2, was composed of 1500 to 1700 Dressel 1 Republican amphorae, the majority of which had the SES (Sestius) stamp on the edge, with an anchor or trident, and a single plant motif (rather than a harpoon). The sinking is estimated to take place between the 2nd and 1st century BCE, probably 110-90 BCE. The first ship (Congloué 1) was a Greek one coming from Sicily and the other (Congloué 2) came from Cosa in southern Etruria, the present Tuscany. All of the twenty Roman amphorae studied come from the Grand Congloué 2 wreck and contain an organic material used for a waterproofing treatment of their internal surfaces. This substance commonly named pitch, was a multi-use product, especially a waterproofing product ensuring sealing of ships but also amphorae and barrels. It was also a weapon of war, once inflamed, to set fire to the enemy fortification (Caillaud, 2011). Concerning amphorae, it was employed to preserve and to transport the content.

Generally, in pitched amphorae, waterproofing materials and

\footnotetext{
* Corresponding authors.

E-mail addresses: hitomi-fujii@aoni.waseda.jp (H. Fujii), carole.mathe@univ-avignon.fr (C. Mathe).
} 
content can be studied along with organic residues. Amphorae have been studied and classified by archaeologists, historians, economists and ceramic petrologists. With the development of molecular archaeometry, analytical techniques began being used to analyse organic matter from amphorae. The characterization of a wide variety of resins in archaeological and historical fields were pioneered by Mills et al. (Mills and White, 1977). Historically, resinous materials were employed in various spheres: the production of unguents, for caulking and waterproofing, and in resinated wine (Evershed et al., 1985; Colombini et al., 2005a; Allevato et al., 2012). One of the most recent studies, done by Font et al., analysed the resinous matter from the interior amphorae surfaces using the Fourier Transform Infrared (FT-IR) spectroscopy and Gas Chromatography-Mass Spectrometry (GC-MS). Then the comparison of two results was performed. A similar analytical study was done by Izzo et al. from pitch of Roman amphorae from Monte Poro, Calabria (Italy) (Izzo et al., 2013).

The aim of this study is to determine the molecular composition of the organic substances used to waterproof the amphorae (pitch) and their content by using FT-IR and GC-MS techniques. Principal Component Analysis (PCA) was performed to differentiate the chemical composition of the twenty samples of pitch. Concerning the content, a comparison of the obtained results has been realized in function to the type of samples studied: pitch and shard.

\section{Experimental}

\subsection{Archaeological samples}

The study is about eleven samples of pitch, referred to as GC2.SN.1 to GC2.SN.11, from amphorae stored in the Fort St Jean (Marseille, France, 2010) and nine samples coming from amphorae stored in the reserves of DRASSM (Department of underwater archaeological research, Aix-les-Milles, France, 2015). Among these nine samples, two are pitch (ref. no. 24251 and 24252) and seven are pitch and shard (ref. no. Li2.83; 24210; 24255; 24265; 24268; 24270; 24281). The macroscopic organic residues called pitch were dark brown coatings from internal surface of the amphorae. The shard samples were clear orange and consisted of different types of clays. The sampling was realized in accordance with the European Standard EN 16085, Conservation of Cultural property - Methodology for sampling from materials of cultural property.

\subsection{Instruments and methods}

\subsubsection{Pitch extraction}

This protocol was performed according to previous works described by Font et al. (2007). $8 \mathrm{mg}$ of samples were extracted during $5 \mathrm{~min}$ with $1.5 \mathrm{~mL}$ of a mixture of acetone/dichloromethane (1:2 v/v) by using ultrasound (PEX 3 sonifier, REUS, Contes, France) $(25 \mathrm{kHz}, 150 \mathrm{~W})$. After a filtration on PTFE filters $(0.45 \mu \mathrm{m}$ of pore size, $25 \mathrm{~mm}$ diameter, VWR International, USA), the extract was treated with $1.0 \mathrm{~mL}$ of dichloromethane and twice with $1.0 \mathrm{~mL}$ of $\mathrm{KOH} 0.5 \mathrm{M}$.

\subsubsection{Wine extraction}

The protocol of the wine extraction was based according to the procedure described by Pecci et al. (2013a,b,c). The samples (50 mg for pitch or $1 \mathrm{~g}$ for shard) were extracted with $\mathrm{KOH}(1 \mathrm{M}, 6 \mathrm{~mL})$ in water by using ultrasound (Sonic Vibra Cell VCX130) during $2 \mathrm{~min}$ and three times. The frequency was fixed at $20 \mathrm{kHz}$. The organic phase was taken by centrifugation ( $4000 \mathrm{ppm} / 15 \mathrm{~min}$ ) and $\mathrm{HCl}$ was added until $\mathrm{pH} 3$. Then $3 \mathrm{~mL}$ of ethyl acetate were added and a vortexing action was applied during $2 \mathrm{~min}$. The supernatant was separated by centrifugation and evaporated to dryness.

\subsection{FT-IR spectroscopy}

The organic remains of the amphorae were powdered and mixed with $200 \mathrm{mg}$ of $\mathrm{KBr}$ (VWR International, USA) and pressed under $10 \mathrm{~T} /$ $\mathrm{cm}^{-2}$ to obtain a $\mathrm{KBr}$ pellet. They were analysed with a Thermo-Nicolet iZ10 FT-IR spectrometer in transmission mode with OMNIC software. All FT-IR spectra were collected in the middle infrared $\left(400-4000 \mathrm{~cm}^{-1}\right)$ recording 32 scans.

\subsection{Gas chromatography-mass spectrometry}

GC-MS analyses were carried out with a Thermo Scientific Focus gas chromatographic system by using a Thermo Scientific $\mathrm{Al} 3000$ autosampler coupled to an ITQ 700 ion trap mass spectrometer (Thermo Fisher Scientific). GC separation was performed on a fused silica capillary column Thermo TG-5MS ( $30 \mathrm{~m}$ length, $0.25 \mathrm{~mm}$ i.d., $0.25 \mu \mathrm{m}$ film thickness). Ion source temperature was $250{ }^{\circ} \mathrm{C}$. Injections were realized in splitless mode and the data were treated with Xcalibur software. Molecular components were eluted using helium at a constant flow of $1.2 \mathrm{~mL} / \mathrm{min}$. The temperature program of the oven was from $50{ }^{\circ} \mathrm{C}$ held $2 \mathrm{~min}, 50-220^{\circ} \mathrm{C}$ at $8{ }^{\circ} \mathrm{C} \cdot \mathrm{min}^{-1}, 220-260{ }^{\circ} \mathrm{C}$ at $2^{\circ} \mathrm{C} \cdot \mathrm{min}^{-1}$, $260-330^{\circ} \mathrm{C}$ at $10^{\circ} \mathrm{C} \mathrm{min}^{-1}$ and helium was the carrier gas. Mass spectrometry was performed using electron ionization mode (EI) at $70 \mathrm{eV}$ of ionization energy and a mass range and spectra were recorded between $\mathrm{m} / \mathrm{z} 50$ and 650 . The injector and detector temperatures were programmed at $250{ }^{\circ} \mathrm{C}$ and interface transfer line temperature was $300^{\circ} \mathrm{C}$. All organic fractions after dryness were derivatised by adding $100 \mu \mathrm{L}$ of $\mathrm{N}, \mathrm{O}$ - Bis (trimethylsilyl) trifluoroacetamide (BSTFA, Thermo, USA) containing $1 \%$ trimethylchlorosilane at $70{ }^{\circ} \mathrm{C}$ for $30 \mathrm{~min}$. The extracts were dried and dissolved in $1 \mathrm{~mL}$ of hexane (Merck, Germany) and filtered with PTFE filters. All the samples were filtered $(0.45 \mu \mathrm{m}$ PTFE filter) before injection and $1 \mu \mathrm{L}$ of each solution was injected in the GC-MS apparatus in triplicate.

The peak assignments were realized on the basis of comparison with retention times and mass spectra of pure standard compounds and by using NIST database (NIST MS Search 2.0).

\subsection{Statistical analysis}

Principal Component Analysis (PCA) with Pearson's correlation was performed using XLSTAT ${ }^{\circledR} 2019$ software. The peak area of each identified molecules from pitch samples has been measured. The relative proportions were computed for each compound. Before analysis a data matrix with 19 columns (variables corresponding to diterpenic compounds) and 20 rows (observations corresponding to samples) was elaborated. A biplot representation was constructed showing both the measured variables and the observations. Confidence ellipses were calculated and expressed on PCA representation $(p<0.05)$.

\section{Results and discussion}

\subsection{FT-IR analysis of pitch}

The characterisation of macroscopic residues from interior surface of the amphorae were performed by FT-IR and GC-MS. The infrared results reveal the presence of organic resinous material and the obtained spectra present several bands characteristic of wood tar. All of the FT-IR spectra show a very similar fingerprint in middle infrared spectroscopy. All of the transmittance profiles are characteristic of wood tar due to the presence of methyl ester derivatives. For example, the infrared spectrum of the sample referred GC2.SN.6. (Fig. 1, Table 1) shows the presence of carboxylic acid dimer at $3700 \mathrm{~cm}^{-1}-3200 \mathrm{~cm}^{-1}$ due to the O-H stretching (Font et al., 2007). Methyl and methylene groups appeared at $2956 \mathrm{~cm}^{-1}, 2928 \mathrm{~cm}^{-1}$ and $2868 \mathrm{~cm}^{-1}$. These bands could be caused by the hydrocarbon skeleton from diterpenic family such as three ring structure (Colombini et al., 2005b; Izzo et al., 


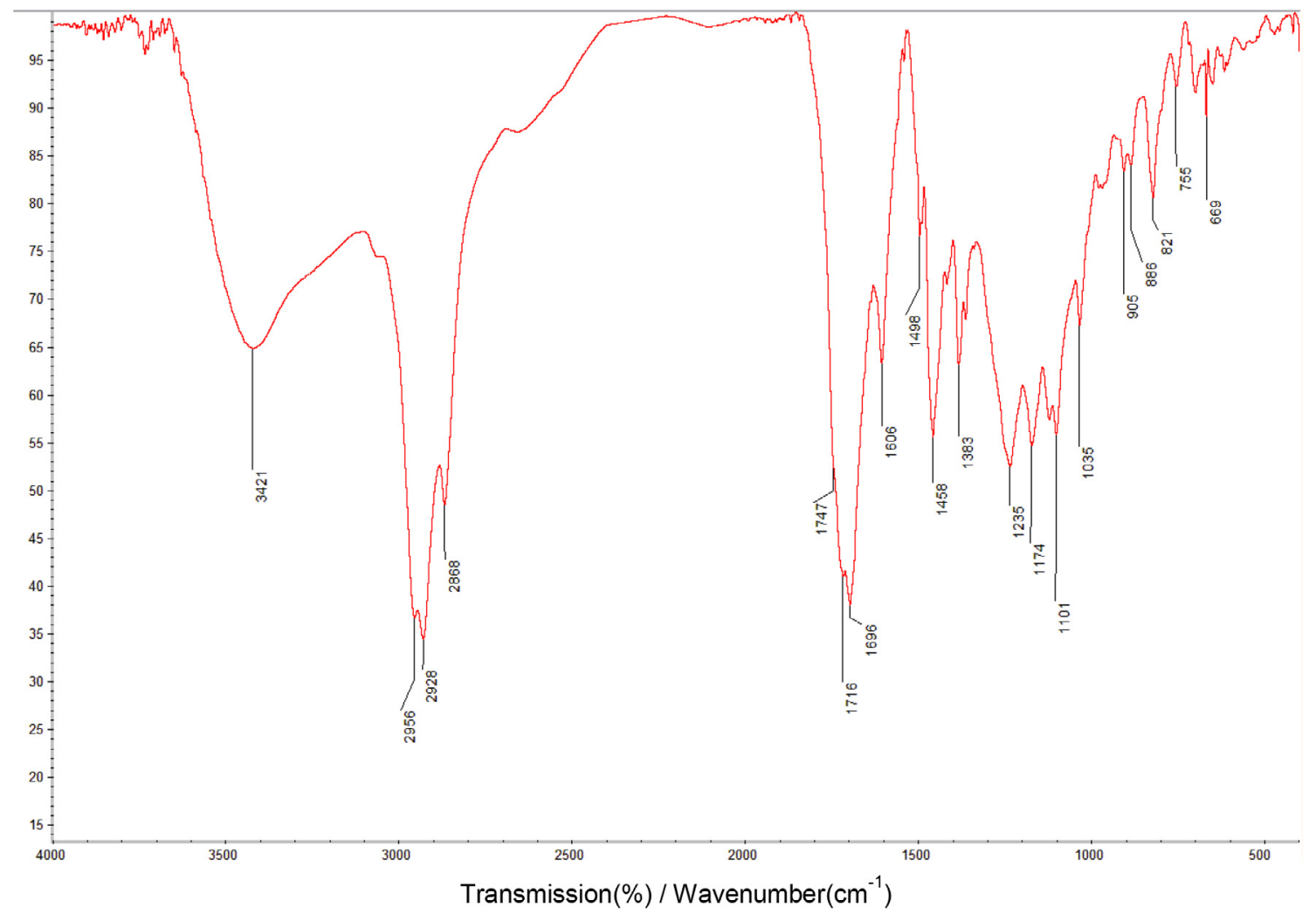

Fig. 1. FT-IR spectrum of sample referred GC.2SN.6.

Table 1

Characteristic bands of FT-IR spectrum of the sample referred GC2.SN.6.

\begin{tabular}{ll}
\hline Characteristic bands & Wavenumber $\left(\mathrm{cm}^{-1}\right)$ \\
\hline$\nu(\mathrm{O}-\mathrm{H})$ & $3700-3200 \mathrm{~cm}^{-1}$ \\
$\nu(\mathrm{C}-\mathrm{H})$ & $2956 \mathrm{~cm}^{-1}, 2928 \mathrm{~cm}^{-1}, 2868 \mathrm{~cm}^{-1}$ \\
$\nu(\mathrm{C}=\mathrm{O})$ & $1716 \mathrm{~cm}^{-1}, 1696 \mathrm{~cm}^{-1}$ \\
$\delta\left(\mathrm{CH}_{3}\right), \delta\left(\mathrm{CH}_{2}\right)$ & $1458 \mathrm{~cm}^{-1}, 1383 \mathrm{~cm}^{-1}$ \\
$\delta(\mathrm{O}-\mathrm{H}), \nu(\mathrm{C}-\mathrm{O})$ & $1235 \mathrm{~cm}^{-1}, 1174 \mathrm{~cm}^{-1}$ \\
$\nu(\mathrm{C}-\mathrm{C})$ ring, $\delta(\mathrm{C}-\mathrm{H})$ ring, $\sigma(\mathrm{C}-\mathrm{H})$ & $1606 \mathrm{~cm}^{-1}, 1498 \mathrm{~cm}^{-1}, 886 \mathrm{~cm}^{-1}$, \\
$\quad$ ring & $881 \mathrm{~cm}^{-1}, 755 \mathrm{~cm}^{-1}$ \\
\hline
\end{tabular}

2013). The bands at $1716 \mathrm{~cm}^{-1}$ and $1696 \mathrm{~cm}^{-1}$ can be attributed to carboxylic acids. The observation of the weak shoulder band appearing at $1747 \mathrm{~cm}^{-1}$ explained the presence of methyl ester (Font et al., 2007). The aromatic ring bands were observed at $1606 \mathrm{~cm}^{-1}, 1498 \mathrm{~cm}^{-1}$, $886 \mathrm{~cm}^{-1}, 821 \mathrm{~cm}^{-1}$ and $755 \mathrm{~cm}^{-1}$. The bands at $1606 \mathrm{~cm}^{-1}$ and $1498 \mathrm{~cm}^{-1}$ are due to symmetric structure of ring (Colombini et al., 2005b). The interaction outside of ring related to $821 \mathrm{~cm}^{-1}$ and $755 \mathrm{~cm}^{-1}$ could be corresponding to the diterpenic structure hydrogenated in high level (Font et al., 2007). The bands at $1458 \mathrm{~cm}^{-1}$ and $1383 \mathrm{~cm}^{-1}$ due to $\mathrm{CH}_{2}$ and $\mathrm{CH}_{3}$ bending are also present and different vibration bands of $\mathrm{COOH}$ are observed at $1235 \mathrm{~cm}^{-1}$ and $1174 \mathrm{~cm}^{-1}$.

\subsection{GC-MS analysis of pitch}

GC-MS analyses were also performed and according to the obtained results, a very similar chemical composition was observed in all samples, proving a homogeneous preparation to waterproof the amphorae studied. Chromatograms show the presence of nineteen chemical compounds and they were characterized according to their retention time and their mass spectra (Table 2). Their occurrence was systemically proved in all samples except 3-hydroxy-dehydroabietic acid and 15-hydroxydehydroabietic acid methyl ester. Retene is one of the main important compound present in the obtained chromatograms (Fig. 2). 18-nor-abietatriene, 19-nor-abietatriene, simonellite and tetrahydroretene are intermediate substances appearing from the thermal degradation of dehydroabietic acid. These abietadienic acids have been transformed by heating procedure for pitch fabrication from natural resin because high temperature conditions or distillation with low oxygen conditions were maintained (Colombini et al., 2005b). This reaction finally leads to the most stable product which is retene. Retene and dehydroabietic acid were considered as markers from Pinaceae family (Colombini et al., 2005a). The occurrence of diterpenic acids with high degree of oxidation such as 3-hydroxydehydroabietic, 7-hydroxydehydroabietic, 7-oxodehydroabietic and 15-hydroxy-7-oxodehydroabietic acids can be explained by a degradation process corresponding to ageing phenomenon and thermal treatment (Colombini et al., 2005a). Aromatized molecules are also detected such as retene, phenanthrene, methylphenanthrene, 18- and 19-norabieta-8,11,13triene, dimethylphenanthrene, tetrahydroretene, simonellite, 9-ethyl10-methylanthracene, 8-isopropyl-1,3-dimethylanthracene. Furthermore, the presence of methyl esters of diterpenic acids was characterized. Dehydroabietic acid methyl ester, 15-hydroxydehydroabietic acid methyl ester and 15-hydroxy-7-oxodehydroabietic acid methyl ester indicate a treatment by destructive distillation of softwood during the preparation of wood tar. The methyl derivatives are absent in the pitch when the resin is heated alone. These methyl ester derivatives were formed with methanol release during pyrolysis of the resinous wood (Colombini et al., 2005b; Izzo et al., 2013; Robinson et al., 1987).

\subsection{PCA analysis of pitch}

According to the gas chromatography results, all of the macroscopic residues presented a very similar chemical composition, but by considering the peak area in relative percentage of the identified diterpenoids (Table 2), it is possible to separate them in two different clusters as PCA study shows (Fig. 3). The three first principal components have permitted to explain $86.63 \%$ of the total variance. After the 


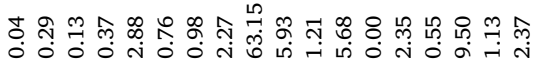

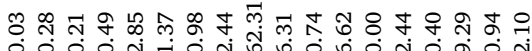
ป 유

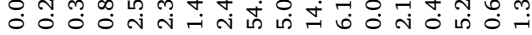

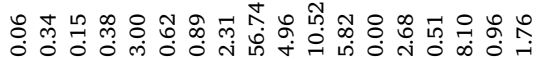

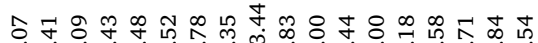

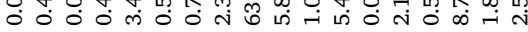

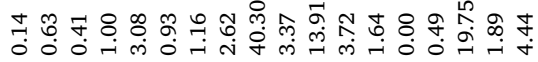

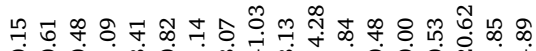

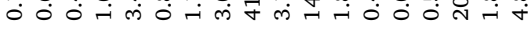

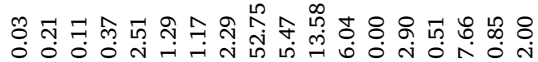
ఫ 0 o 品

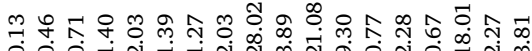
?़े 는

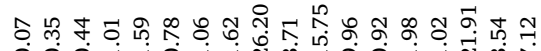
ลิ

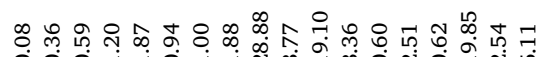

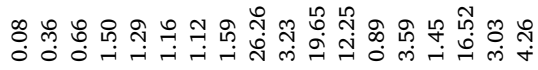

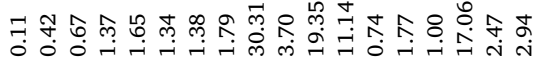
a

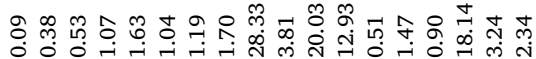
$\stackrel{8}{\circ}$ น กิ้ †ํำ กิ่

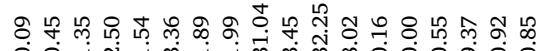
กิ่ (1)

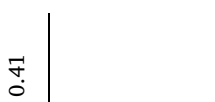

examination of the three dimensions, the components 1 and 3 have been considered as the most representative factors according to the variable distribution. The biplot representation (Fig. 3) permitted to show the main chemical molecules distribution in relation to the components. The component 1 was mainly characterized by a high proportion in retene, 8-isopropyl-1.3-dimethylanthrene, dimethylphenanthrene and the component 3 was defined by a high proportion in 15hydroxydehydroabietic acid methyl ester and dehydroabietic acid. Examining the score plot in the area defined by the first three principal components, a separation of the samples into two groups was found according to the different alteration markers from pitch. The first group defined by samples no GC2.SN1 to GC2.SN11, 24,251 and 24252. The second group is defined by ten samples referred from Li2.83, 24 250, 24555, 24265, 24268, 24270, 27281 (Fig. 4). The cluster No 1 is characterized by a high proportion in dehydroabietic acid and their respective alteration compounds as the methyl esters, 3-hydroxy, 7oxo-, nor-abietane derivatives. The cluster No 2 was defined by an important concentration in retene and others aromatic compounds.

\subsection{GC-MS results from the content}

The analytical study of the amphorae content was performed using GC-MS on both pitch samples and amphorae shards. Generally, the same molecules have been identified in pitch and shards. However, the number of compounds detected is higher in the pitch samples. The 18 pitch samples were studied and 7 wine acids were identified on the chromatograms respectively obtained (Fig. 5). Analysis of the shards showed the presence of certain wine acids: succinic, glutaric and vanillic acids (Pecci et al., 2013b,c; Singleton, 1996). The 7 shards of amphorae have been studied and the results are quite similar. On the other hand, benzoic acid, succinic acid and fumaric acid have not been observed in the shards. Thus, the obtained results show that the content of these amphorae was red wine, by the presence of syringic acid, specific marker of its color (Guasch-Jané et al., 2006, 2004). However, it is important to point out that syringic acid is not a biomarker for red wine and can be found free in several plant products, as is malvidin, from which the syringic acid (in the case of our protocol used to extract the wine markers) is released by alkaline fusion. That is why the interpretation of red wine is based on both the presence of the wine markers, as well as the context.

The results of identification correspond to wine acids and fatty acids (Table 3). The presence of wine markers such as tartaric and syringic acids (Stern et al., 2008; Garnier and Valamoti, 2016) was confirmed by the chromatogram in organic remains and in shards (Fig. 5, Table 3). In the other acids associated with wine, the amount of vanillic acid was high and subsequent acids were benzoic, succinic, glutaric and fumaric. Thus, these results indicate that the Grand Congloue 2 amphorae contained wine. The yield wine acid in pitch was more than in shard. This could be explained by the fact that the shard holds the lower amount of residues because of internal waterproofing materials such as a pine pitch. Benzoic acid, succinic acid and fumaric acid were not observed in shards. Fatty acids such as octanoic (C8:0), nonanoic (C9:0), decanoic (C10:0), palmitic (C16:0) and stearic (C18:0) acids were detected. Azelaic acid is known to be a degradation product from oleic acid (Dudd et al., 1998). The sterols from animal origin were not observed and $\mathrm{C}_{16: 0}$ to $\mathrm{C}_{18: 0}$ ratios were not a big enough to determinate plant origin. Therefore these lipids in archaeological material are considered to have occurred during biodegradation processes (Oudemans and Boon, 1991).

\section{Conclusion}

This paper deals with the analytical study of pitched Roman amphorae. The characterization of pitch has shown the presence of nineteen compounds corresponding to diterpenoids and respective alteration compounds of Pinaceae family (Pinus spp.). Specific chemical 


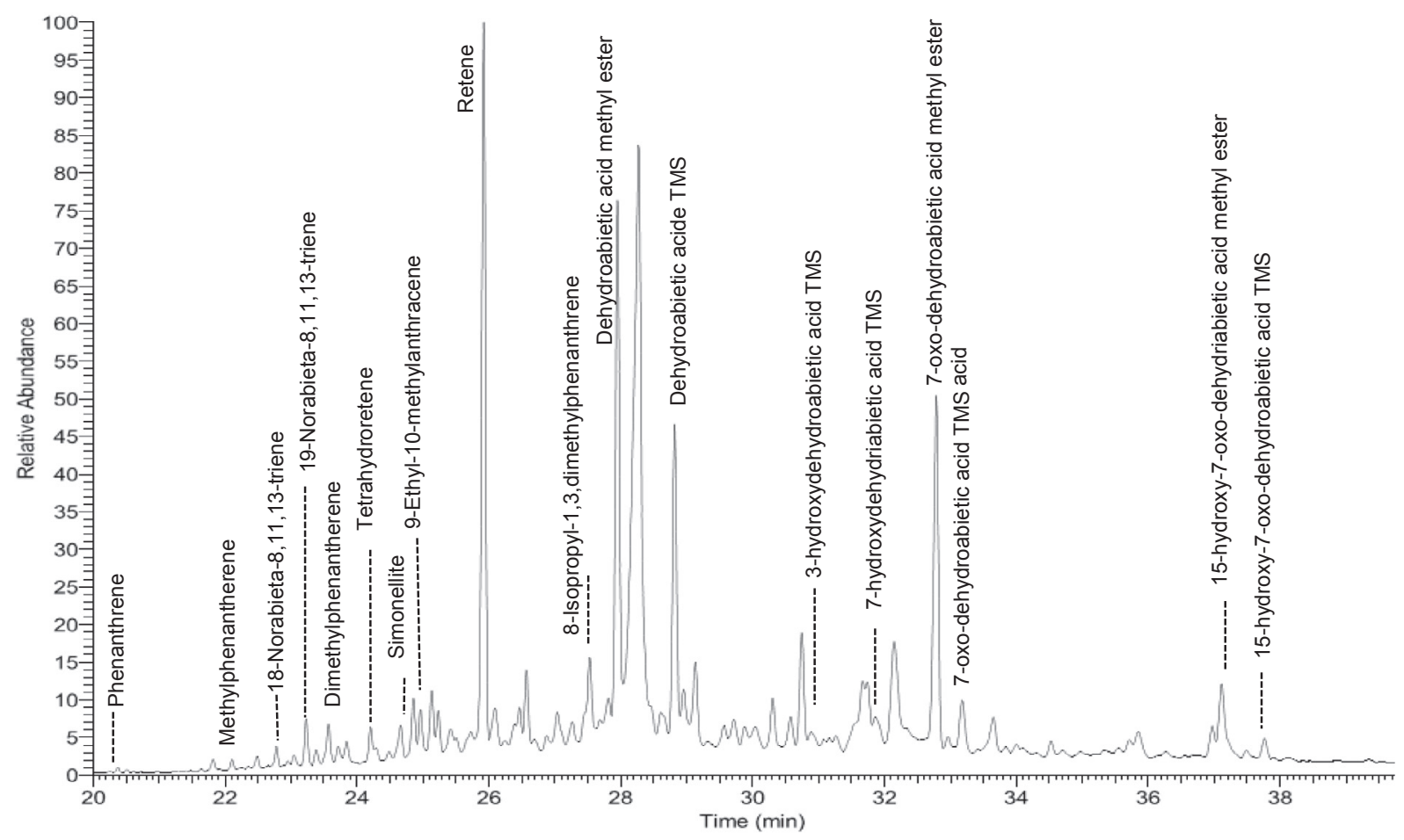

Fig. 2. GC-MS TIC chromatogram of organic remains sample referred GC2SN6 (TMS: trimethylsilylation).

markers such as dehydroabietic acid and 7-oxodehydroabietic acid are usually found in well-conserved diterpenic resins. 3-Hydroxy, 15-hydroxydehydroabietic acid and derivatives occurred due to the oxidation process of the resinous material. The aromatic compounds such as nor- abietatriene, retene, phenanthrene and anthracene were the result of an anthropic alteration caused by the high temperatures. In addition, the presence of diterpenic acid methyl esters such as dehydroabietic acid methyl ester indicates a pyrogenic treatment of softwoods. According to

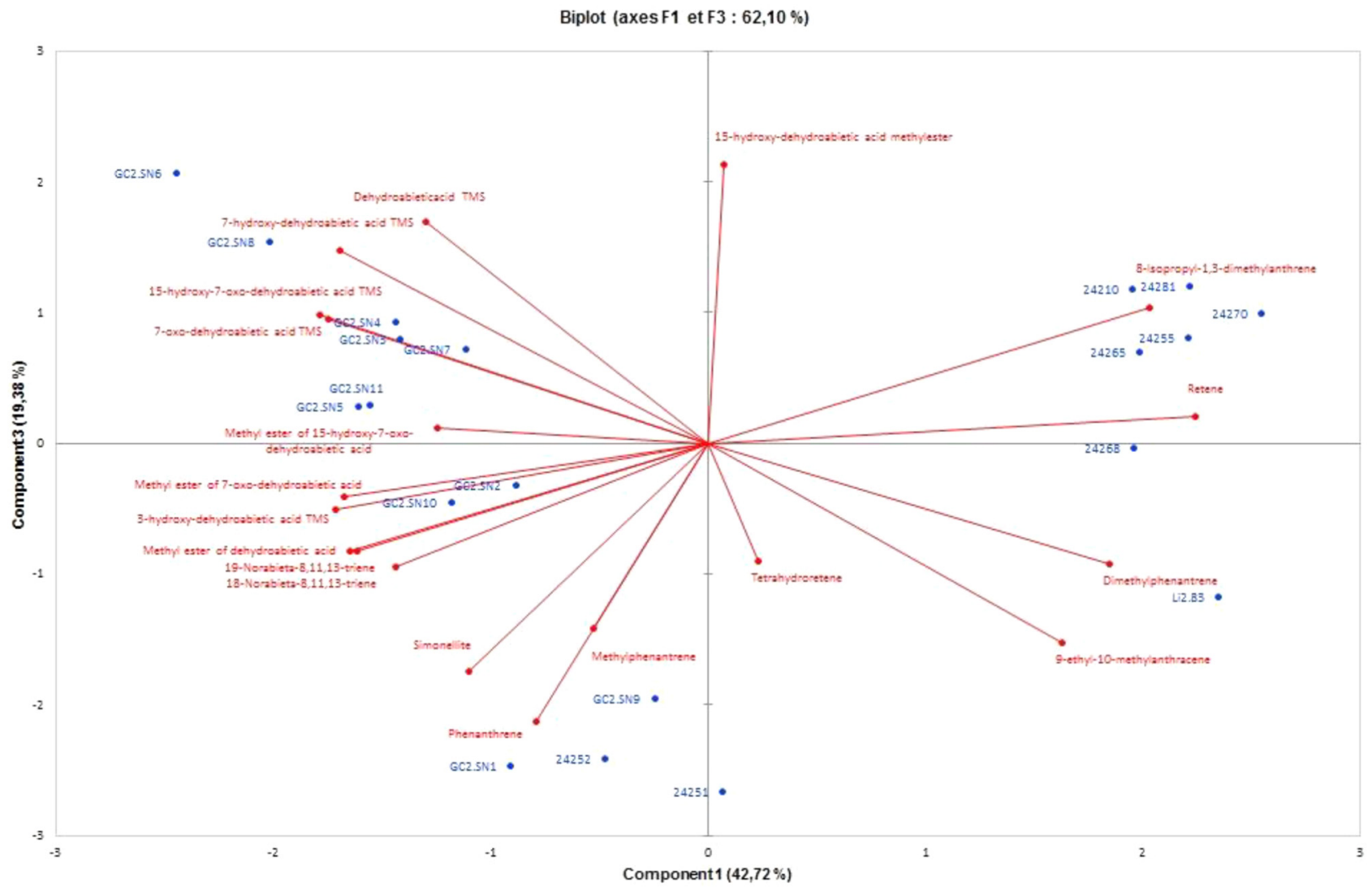




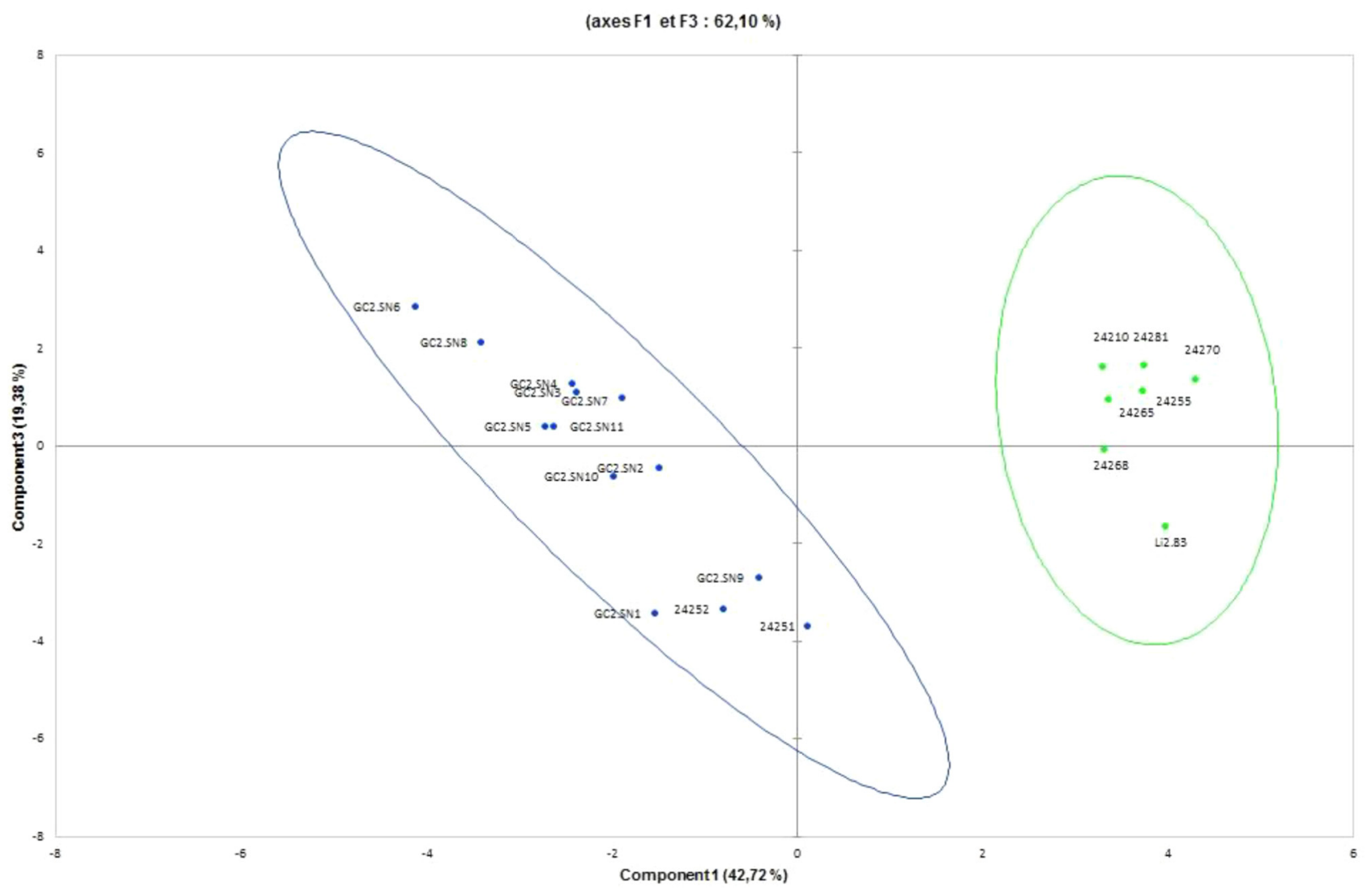

Fig. 4. Principal component analysis of pitch samples.
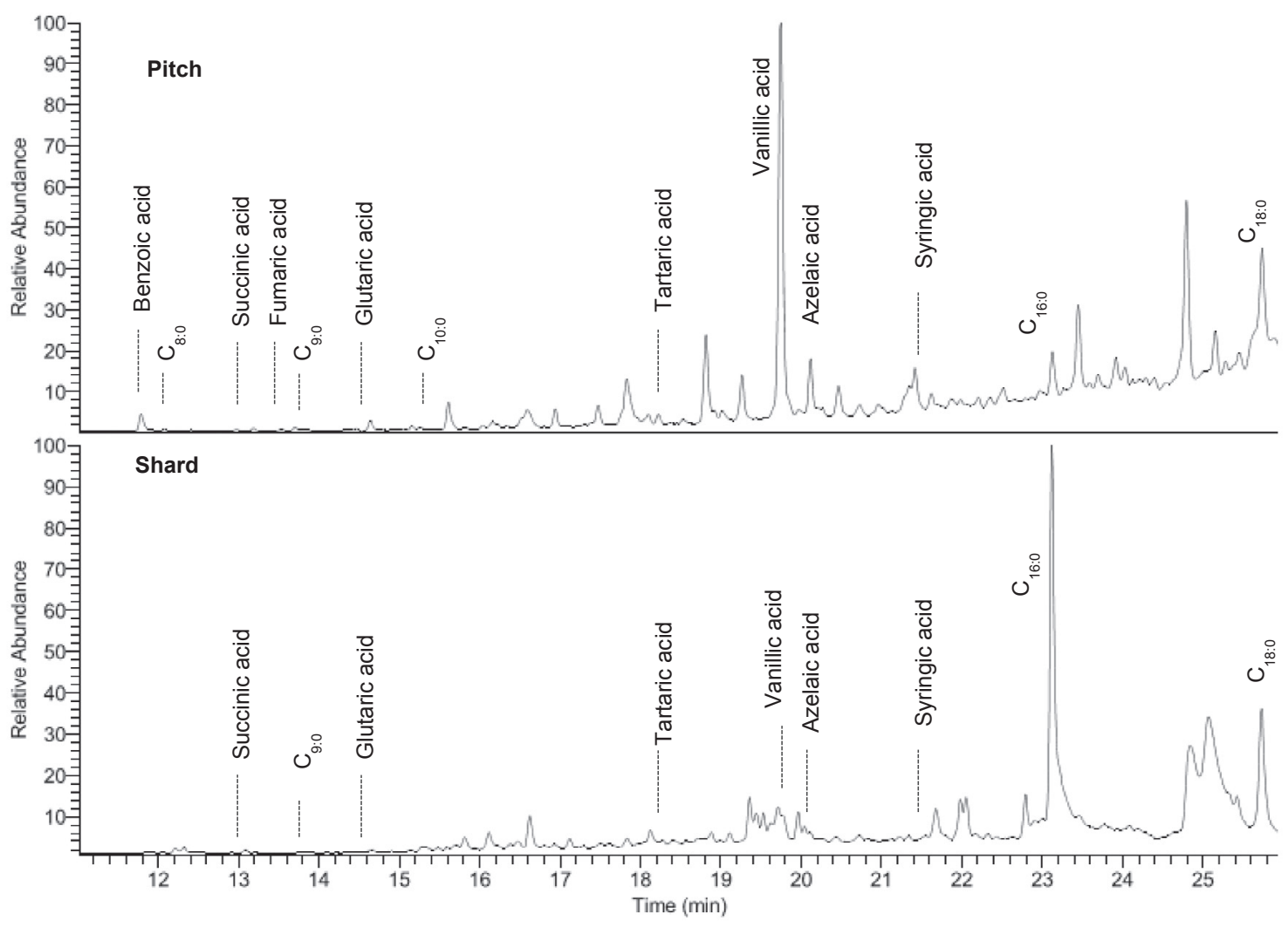

Fig. 5. GC-MS TIC chromatogram of pitch and shard samples referred 24270. 


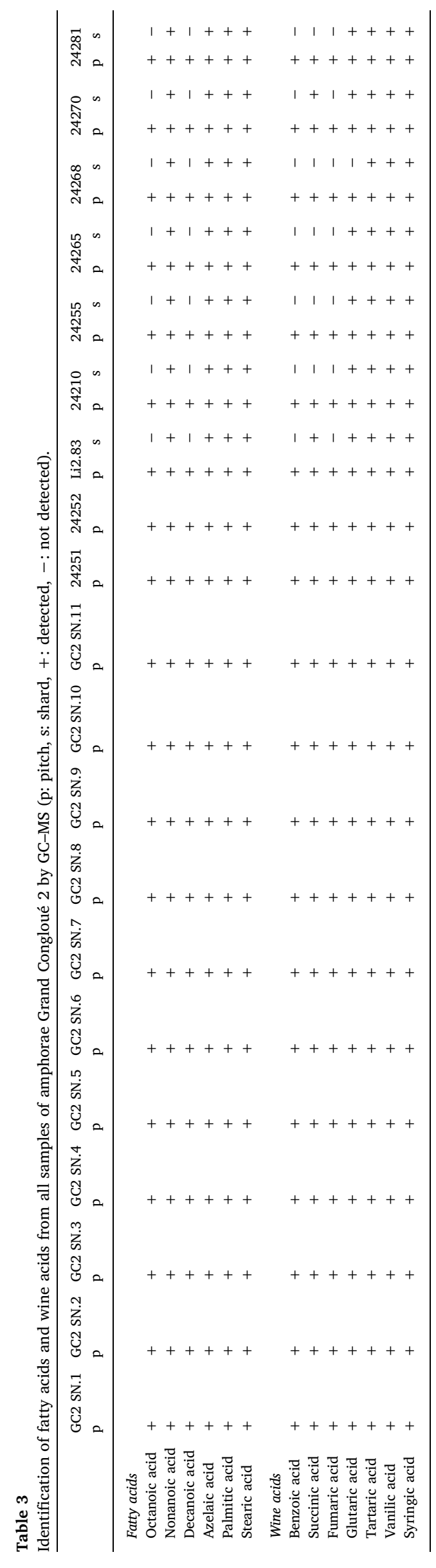

the results obtained by GC-MS, it is possible to identify the pitch as a wood tar from Pinaceae family with a very similar chemical composition. The PCA analysis permitted to cluster all of the twenty studied amphorae in two groups. The first one is characterized by a pitch with a less proportion in thermal degradation compounds such a retene and aromatic derivatives and so a high proportion in dehydroabietic acid and 7-oxodehydroabietic acid. For the second one, the reverse results were observed. The observations seem to indicate that all of the amphorae of Grand Congloue 2 wreck were not pitched on the same manner.

Concerning the analysis of the amphorae content, azelaic, palmitic and stearic acids were observed in all pitch and shard samples. It is common to find fatty acids in amphorae that have contained wine. Markers of wine such as tartaric and syringic acids have been also identified, both in the pitch and the shard. Other constituents of wine such as benzoic, succinic, fumaric, glutaric and vanillic acids have also been detected. It is interesting to note that amphorae of Grand Congloué 2 were preserved in the marine environment and the number of wine acids detected has permitted to clearly define that this particular archaeological context contributes to a high quality conservation state. The comparison of pitch and shard from the same amphorae has shown a higher qualitative and quantitative proportions of wine markers in pitch instead of shard.

\section{Author contributions}

H.F. analysed all archaeological samples and developed protocols. J.M. performed the PAC computational study. D.A analysed also samples by FT-IR. F.O. conceptualized and performed the archaeological study. C.M. and C.V. supervised the research. H.F., C.M. and C.V. discussed the results. H.F, C.M and CV wrote the paper.

\section{Declaration of Competing Interest}

The authors declare that they have no known competing financial interests or personal relationships that could have appeared to influence the work reported in this paper.

\section{Acknowledgments}

The authors thank Mrs Nathalie Huet, Research Engineer, in charge of preventive conservation and furniture management, Department of Underwater Archaeological Research (DRASSM). Theater Dream's Company (Japan) is also thanked for funding $\mathrm{PhD}$ study source. The authors also thank the reviewers for their constructive comments.

\section{References}

Allevato, E., Buonincontri, M., Vairo, M., Pecci, A., Cau, M.A., Yoneda, M., De Simone, G.F., Aoyagi, M., Angelelli, C., Matsuyama, S., Takeuchi, K., Di Pasquale, G., 2012. Persistence of the cultural landscape in Campania (Southern Italy) before the AD 472 Vesuvius eruption: archaeoenvironmental data. J. Archaeol. Sci. 39, 399-406. https://doi.org/10.1016/j.jas.2011.09.026.

Caillaud, C., 2011. Vitis allobrogica vinum picatum, la production de vin sur le territoire de la cité de Vienna: master 2 thesis. university Lyon 2.

Colombini, M.P., Modugno, F., Ribechini, E., 2005a. Direct exposure electron ionization mass spectrometry and gas chromatography/mass spectrometry techniques to study organic coatings on archaeological amphorae. J. Mass Spectrom. 40, 675-687. https://doi.org/10.1002/jms.841.

Colombini, M.P., Giachi, G., Modugno, F., Ribechini, E., 2005b. Characterisation of organic residues in pottery vessels of the Roman age from Antinoe (Egypt). Microchem. J. XI Ital. Hungarian Symp. Spectrochem. 79, 83-90. https://doi.org/10.1016/j. microc.2004.05.004.

Dudd, S.N., Regert, M., Evershed, R.P., 1998. Assessing microbial lipid contributions during laboratory degradations of fats and oils and pure triacylglycerols absorbed in ceramic potsherds. Org. Geochem. 29, 1345-1354. https://doi.org/10.1016/S01466380(98)00093-X.

Evershed, R.P., Jerman, K., Eglinton, G., 1985. Pine wood origin for pitch from the Mary Rose. Nature 314, 528-530.

Font, J., Salvadó, N., Butí, S., Enrich, J., 2007. Fourier transform infrared spectroscopy as a suitable technique in the study of the materials used in waterproofing of 
archaeological amphorae. Anal. Chim. Acta 598, 119-127. https://doi.org/10.1016/ j.aca.2007.07.021.

Garnier, N., Valamoti, S.M., 2016. Prehistoric wine-making at Dikili Tash (Northern Greece): integrating residue analysis and archaeobotany. J. Archaeol. Sci. 74, 195-206. https://doi.org/10.1016/j.jas.2016.03.003.

Guasch-Jané, M.R., Ibern-Gómez, M., Andrés-Lacueva, C., Jáuregui, O., LamuelaRaventós, R.M., 2004. Liquid chromatography with mass spectrometry in tandem mode applied for the identification of wine markers in residues from ancient Egyptian vessels. Anal. Chem. 76, 1672-1677. https://doi.org/10.1021/ac035082z.

Guasch-Jané, M.R., Andrés-Lacueva, C., Jáuregui, O., Lamuela-Raventós, R.M., 2006. The origin of the ancient Egyptian drink Shedeh revealed using LC/MS/MS. J. Archaeol. Sci. 33, 98-101. https://doi.org/10.1016/j.jas.2005.06.013.

Izzo, F.C., Zendri, E., Bernardi, A., Balliana, E., Sgobbi, M., 2013. The study of pitch via gas chromatography-mass spectrometry and Fourier-transformed infrared spectroscopy: the case of the Roman amphoras from Monte Poro, Calabria (Italy). J. Archaeol. Sci. 40, 595-600. https://doi.org/10.1016/j.jas.2012.06.017.

Mills, J.S., White, R., 1977. Natural resins of art and archaeology; their sources, chemistry and identification. Stud. Conserv. 22, 12-31.

Olmer, F., Bohbot, H., Joliot, C., Mathe, C., 2015. In: Histoire d'epave. Origine, fonction et destin de la cargaison d'amphores du Grand Congloué, pp. 2

Oudemans, T.F.M., Boon, J.J., 1991. Molecular archaeology: analysis of charred (food) remains from Prehistoric pottery by pyrolysis—gas chromatography/mass spectrometry. J. Anal. Appl. Pyrol. 20, 197-227. https://doi.org/10.1016/0165 2370(91)80073-H.

Pecci, A., Giorgi, G., Salvini, L., Cau Ontiveros, M.Á., 2013a. Identifying wine markers in ceramics and plasters using gas chromatography-mass spectrometry. Experimental and archaeological materials. J. Archaeol. Sci. 40, 109-115. https://doi.org/10 1016/j.jas.2012.05.001.

Pecci, A., Cau Ontiveros, M.Á., Garnier, N., 2013b. Identifying wine and oil production: analysis of residues from Roman and Late Antique plastered vats. J. Archaeol. Sci. 40 4491-4498. https://doi.org/10.1016/j.jas.2013.06.019.

Pecci, A., Cau Ontiveros, M.Á., Valdambrini, C., Inserra, F., 2013c. Understanding residues of oil production: chemical analyses of floors in traditional mills. J. Archaeol. Sci. 40, 883-893. https://doi.org/10.1016/j.jas.2012.07.021.

Robinson, N., Evershed, R.P., Higgs, W.J., Jerman, K., Eglinton, G., 1987. Proof of a pine wood origin for pitch from Tudor (Mary Rose) and Etruscan shipwrecks: application of analytical organic chemistry in archaeology. Analyst 112, 637-644. https://doi. org/10.1039/AN9871200637.

Singleton, V.L., 1996. An enologist's commentary on ancient wines. In: The Origins and Ancient History of Wine. Gordon and Breach, pp. 67-78.

Stern, B., Heron, C., Tellefsen, T., Serpico, M., 2008. New investigations into the Uluburun resin cargo. J. Archaeol. Sci. 35, 2188-2203. https://doi.org/10.1016/j. jas.2008.02.004 